\title{
Study on Fracture and Permeability Characteristics of Unloading Rock with High Water Pressure
}

\author{
Zhi-tao Ma $\mathbb{D}^{1,2}$ Yong-qiang Cui $\mathbb{D}^{1},{ }^{1}$ Ke-yu Lu $\mathbb{D},{ }^{1}$ Dai-fu Song $\mathbb{D},{ }^{1}$ and Ya-chao Yang $\mathbb{D}^{1}$ \\ ${ }^{1}$ College of Energy and Mining Engineering, Shandong University of Science and Technology, Qingdao, Shandong 266590, China \\ ${ }^{2}$ State Key Laboratory of Mining Disaster Prevention and Control Co-founded by Shandong Province and the Ministry of Science \\ and Technology, Shandong University of Science and Technology, Qingdao 266590, China
}

Correspondence should be addressed to Yong-qiang Cui; wdjmcyq@163.com

Received 2 November 2020; Revised 3 January 2021; Accepted 8 January 2021; Published 20 January 2021

Academic Editor: Wangcheng Zhang

Copyright ( $\odot 2021$ Zhi-tao Ma et al. This is an open access article distributed under the Creative Commons Attribution License, which permits unrestricted use, distribution, and reproduction in any medium, provided the original work is properly cited.

\begin{abstract}
Research on the damage and seepage characteristics of unloading rock with high water pressure can help to further understand the mechanism of water inrush in deep mine floor and prevent water inrush. This paper used the RFPA2D-flow finite element software to study the failure and seepage characteristics of unloading rock with high water pressure and high stress and comparatively analyzed the failure modes and seepage characteristics of unloading rock with and without water pressure. The effects of different water pressure differences on the failure of unloading rock and the law of seepage were investigated by analyzing the change of acoustic emission and permeability coefficient with stress. The results showed that the unloading rock without water pressure was brittle failure, and the initial damage of the unloading model with water pressure was earlier than that of the model without water pressure and showed greater brittleness, and its cracks first break through at the bottom of the sample with higher osmotic pressure. With the increase in unloading, the permeability of rock increased gradually until it appeared an abrupt change. The failure mode and permeability law of the rock with different water pressure differences were basically the same, but the greater the pressure difference, the smaller the effective unloading capacity when the permeability coefficient changes suddenly, and the greater the possibility of water inrush in the rock.
\end{abstract}

\section{Introduction}

From the perspective of the nature of mechanics, the excavation and support of underground engineering belong to the category of alternating loading and unloading mechanics. In many cases, the unloading rock is simultaneously affected by groundwater seepage pressure. For example, most roof and floor water inrush failures in underground mining are caused by water pressure and unloading.

In [1], the unloading test of rock under high confining pressure and high water pressure was conducted. The analysis found that the degree of unloading damage after the rock reached the peak strength was greater than that before the peak. The existence of water pressure weakened the unloading strength of the rock in the process of unloading. In [2], the mechanical properties and failure mechanism of rock under loading and unloading were compared and analyzed by RFPA2D. It was found that the unloading failure was mainly tensile failure, and the angle between the failure surface and the direction of the maximum principal stress was less than that of the loading failure surface. In paper [3], the fluid-solid coupling of rock mass with complex fractures was studied, and it was found that the hydraulic gap width of the fractures was negatively correlated with the stress. In the article [4], a triaxial compression test of fractured rock mass under seepage action was carried out, the fluid-solid coupling equation of a single fracture under triaxial conditions was proposed, and the mechanism of stress affecting fracture permeability was revealed. In [5], based on the principle of effective stress, the mechanical mechanism of crack propagation under water pressure was studied. In [6], the UDEC numerical analysis software was used to study the permeability characteristics of fractured rock masses under various stress states, and it was obtained that the law of equivalent 
permeability coefficient was influenced by the normal closure and the dilatation effect of fractures. In [7], three coupling evaluation models (elastic and plastic strainseepage coupling, rheology-seepage coupling, and variable parameter rheology-seepage coupling) were proposed, and FLAC3D software was used to analyze the delayed water inrush and its seepage mechanism in the fractured structural zone of the mine. In [8], RFPA2D-flow calculation program was applied to simulate and analyze the whole process of fracture formation and transfixion of the floor (including concealed small faults) under the joint action of mining and high confined water and revealed the water inrush evolution mechanism of the whole floor under mining and water pressure. In [9], the FLUENT module of ANSYS was used to study the nonlinear characteristics of fluid flow and the variation of critical hydraulic gradient with the opening, roughness coefficient, and the number of intersection points of the crack grid. In [10], the Navier-Stokes equation was solved using the COMSOL metaphysics program, and the seepage change characteristics of a single fracture with different shear displacements were calculated, and the change rules of equivalent hydraulic gap width, mechanical gap width, and volume flow velocity associated with the shear displacement of the rock were obtained. It can be seen from the above that previous studies have deepened the understanding of rock permeability and deformation characteristics under the coupled action of the rock seepage field and stress field. However, the influence of water pressure difference on the confining pressure unloading rock still needs to be explored to further understand its regularity.

In this paper, considering the influence of water pressure difference on confining pressure unloading rock, RFPA2D-flow software was used to simulate the confining pressure unloading rock with and without water pressure and the confining pressure unloading rock under different water pressure differences. According to the change of acoustic emission and permeability coefficient with stress, the initiation of new fractures, the expansion of fractures, and the evolution of permeability of seepage rock were studied in the process of unloading. It has important practical significance for the safe construction and technical guidance of underground engineering.

\section{Principle of RFPA2D-Flow}

The seepage of unloaded rock mass essentially means that the rock is subjected to stress and water pressure. And, the cracks in the rock stratum are generated, expanded, and penetrated until the rock stratum is unstable and damaged. It is a typical fluid-solid coupling process. The porous media deform under the fluid load, which in turn affects the distribution and magnitude of the flow field load.

RFPA2D-flow uses elastic mechanics as a stress analysis tool, elastic damage theory, and modified Mohr-Coulomb failure criterion as a medium deformation and failure analysis method to conduct a coupled analysis of stress, deformation, and seepage evolution during rock failure [11]. In the elastic state, the mesoelement satisfies the relationship between the permeability-stress-strain function, and the permeability of the element increases sharply after the element is damaged and ruptured. Then, through the coupling loop iteration, the coupling calculation between the element's permeability and stress is realized. The classical equation of seepage coupling theory is as follows.

Equilibrium equation is as follows:

$$
G \nabla^{2} u_{j}-(\lambda+G) \frac{\partial \varepsilon_{v}}{\partial x_{j}}-\frac{\partial p}{\partial x_{j}}+f_{j}=0 .
$$

Geometric equation is as follows:

$$
\left\{\begin{array}{l}
\varepsilon_{i j}=\frac{1}{2}\left(u_{i, j}+u_{j, i}\right), \\
\varepsilon_{v}=\varepsilon_{11}+\varepsilon_{22}+\varepsilon_{33} .
\end{array}\right.
$$

Constitutive equation is as follows:

$$
\sigma_{i j}^{\prime}=\sigma_{i j}-p \delta_{i j}=\lambda \delta_{i j} \varepsilon_{v}+2 G \varepsilon_{i j} .
$$

Seepage equation is as follows:

$$
k \nabla^{2} p=\frac{1}{S} \frac{\partial p}{\partial t}-\frac{\partial \varepsilon_{v}}{\partial t}
$$

Seepage and stress coupling equation is as follows:

$$
k(\sigma, p)=\xi k_{0} e^{-\beta\left(\left(\sigma_{i j} / 3\right)-a p\right)} .
$$

In the formula, $\lambda$ and $G$ are Lame coefficient and shear modulus, respectively; $\sigma_{i j}$ and $\sigma_{i j}^{\prime}$ are the total stress and effective stress, respectively, and their unit is $\mathrm{Pa} ; x_{j}, u_{j}$, and $f_{j}$ are coordinates, displacement, and volume forces in the direction of $j ; \varepsilon_{i j}$ and $\varepsilon_{v}$ are total strain and volumetric strain; $\delta$ is the Kronecker constant; $k$ is the permeability coefficient; $S$ is the water storage coefficient; and $\xi, \beta$, and $a$ are the permeability coefficient jump ratio, coupling coefficient, and pore water pressure coefficient, respectively. The $p$ is the pore water pressure, and the unit is Pa. $t$ is time, and the unit is $\mathrm{s}$.

In the process of stress-seepage coupling calculation, in order to make the rock unit better realize the coupling of the seepage field and stress field, the equivalent permeability coefficient was calculated according to the stress and pore water pressure of the model unit at the end of each cycle, and then the permeability coefficient was reassigned to each element of the model. It should connect the evolution of pores and fractures in rock with the permeability coefficient so that the seepage field and stress field interact with each other [12].

\section{Numerical Experiment Model}

3.1. Parameters of the Model. According to the principles of the RFPA2D-flow simulation software, a numerical simulation model was established to carry out loading and unloading seepage tests on rock with water pressure. Figure 1 shows the two-dimensional plane stress thin plate model. The width of the model was $50 \mathrm{~mm}$, and the height was $80 \mathrm{~mm}$. The model was divided into $100 \times 160=16,000$ units. The physical and mechanical parameters of the model are shown in Table 1. 


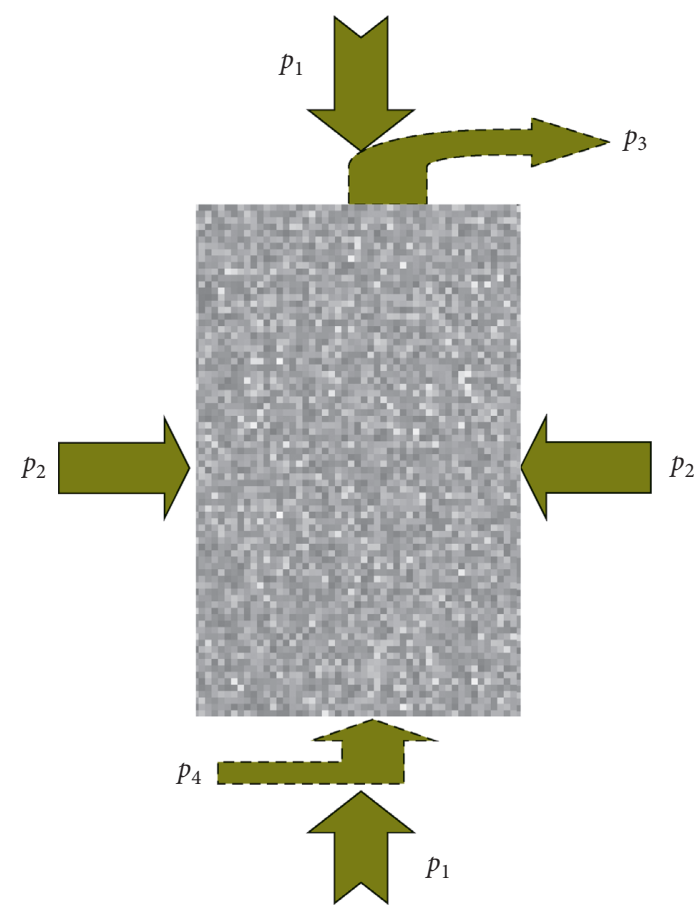

Figure 1: The schematic diagram of the model.

The bottom boundary of the model was imposed with a displacement constraint in the vertical direction; an axial pressure $p_{1}$ was applied on the top, and a confining pressure $p_{2}$ was applied on all sides, and upper water pressure $p_{3}$ and lower water pressure $p_{4}$ are applied on the top and bottom boundaries of the model, respectively. The step-by-step loading method is adopted, the seepage time step is set as 1 day, and the maximum iteration number is set as 300 .

3.2. Process of Simulation. Considering that if the confining pressure of the rock is released after the peak, the stress has exceeded the yield strength of the rock, and the specimen is in a state of failure. The Mohr-Coulomb strength criterion was used to simulate the unloading of seepage rock before the peak [13]. The simulation steps were as follows:

(1) First of all, we applied axial pressure $p_{1}$ and confining pressure $p_{2}$ at the same time and kept them equal at all times. After loading to a predetermined pressure step by step, we applied certain pore water pressures $p_{4}$ and $p_{3}$ at the bottom and upper boundaries of the model to realize the rock seepage simulation.

(2) The confining pressure $p_{2}$ was kept unchanged, and displacement control was used to carry out the axial loading on the rock model. The loading displacement increment was $\Delta S=0.005 \mathrm{~mm}$ until the axial pressure value $p_{1}$ reached a certain state before rock failure. That was the critical unloading point. The critical value of the unloading stress should be much greater than the compressive strength under uniaxial compression and less than the compressive strength of the three-axis test under the corresponding confining pressure [14]. The starting point of unloading in this simulation was taken as $75 \%$ of the maximum strength of three-axis compression.

(3) The axial pressure $p_{1}$ was kept unchanged, and the confining pressure $p_{2}$ was gradually removed Each unloading stage $p=0.2 \mathrm{MPa}$ until the model was damaged.

3.3. Validation of the Model. According to the above process, the numerical simulation model of the test was established. The model needed to be tested to verify its reliability. In the process of verification, the models with different grid sizes were used for calculation. The material parameters are shown in Table 1 . It can be seen from Figure 2 that the larger the grid size of the model, the higher the peak intensity; the smaller the grid size, the lower the peak intensity. When the grid size was less than $0.5 \mathrm{~mm}$, the peak strength tended to be stable. However, the smaller the grid size, the more the number of elements and the longer the time of calculation. Therefore, $0.5 \mathrm{~mm}$ was selected as the optimal grid size after comprehensive consideration.

In [15], a cylindrical marble specimen with a diameter of $50 \mathrm{~mm}$ and a height of $100 \mathrm{~mm}$ was used to carry out the prepeak unloading tests with high confining pressure $(20 \mathrm{MPa})$ under nonwater pressure and high water pressure $(10 \mathrm{MPa})$ conditions. It is found that the existence of high water pressure reduces the initial confining pressure, that is, reduces the effective normal stress on the fracture surface and failure surface of rock, accelerates the fracture of rock, and reduces the strength of rock. Under the condition of high water pressure, the unloading rock shows more brittle failure, and its failure is more severe than that without water pressure, and its strength is significantly lower than that without water pressure.

RFPA-flow software was used to simulate the above experiment. A two-dimensional stress model with a width of $50 \mathrm{~mm}$ and a height of $100 \mathrm{~mm}$ was established. The grid was divided into $100 \times 200=20,000$ square elements. The physical and mechanical parameters of the model were adopted in reference [15].

The numerical simulation results of the test models with and without water pressure were compared with the results of the experiment in reference [15]. It can be found from Figure 3 that the stress-strain curve of the results of the simulation was approximately consistent with the results of experimental. The peak strength of the prepeak unloading test without water pressure was $148 \mathrm{MPa}$, and the peak strength of the prepeak unloading test with water pressure was $133 \mathrm{MPa}$. The peak strength of the simulation results without water pressure was $152 \mathrm{MPa}$, and the peak strength of the simulation results with water pressure was $128 \mathrm{MPa}$. There was little difference between the simulation results and the test results. Therefore, according to the verification in this section, the mesh and calculation of this numerical model are feasible. 
TABLE 1: Mechanical parameters of the model.

\begin{tabular}{lcccccccc}
\hline Parameter & $\begin{array}{c}\text { Elastic } \\
\text { modulus } \\
(\mathrm{GPa})\end{array}$ & $\begin{array}{c}\text { Poisson's } \\
\text { ratio } \\
(\mu)\end{array}$ & $\begin{array}{c}\text { Compressive } \\
\text { strength }(\mathrm{MPa})\end{array}$ & $\begin{array}{c}\text { Tensile } \\
\text { strength } \\
(\mathrm{MPa})\end{array}$ & $\begin{array}{c}\text { Residual } \\
\text { compressive } \\
\text { strength }(\mathrm{MPa})\end{array}$ & $\begin{array}{c}\text { Permeability } \\
\text { coefficient } K_{0} \\
(\mathrm{~m} / \mathrm{d})\end{array}$ & $\begin{array}{c}\text { Water } \\
\text { pressure } \\
\text { coefficient }(\alpha)\end{array}$ & $\begin{array}{c}\text { Coupling } \\
\text { coefficient } \\
(\beta)\end{array}$ \\
\hline Value & 10 & 0.22 & 100 & 10 & 1 & 0.2 & 0.6 & 0.2 \\
\hline
\end{tabular}

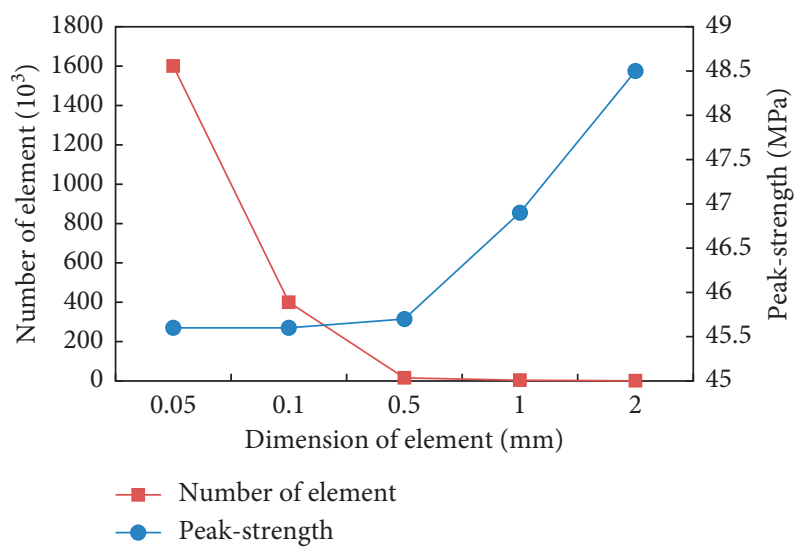

FIGURE 2: The relationship curve between peak strength, number of element, and grid size.

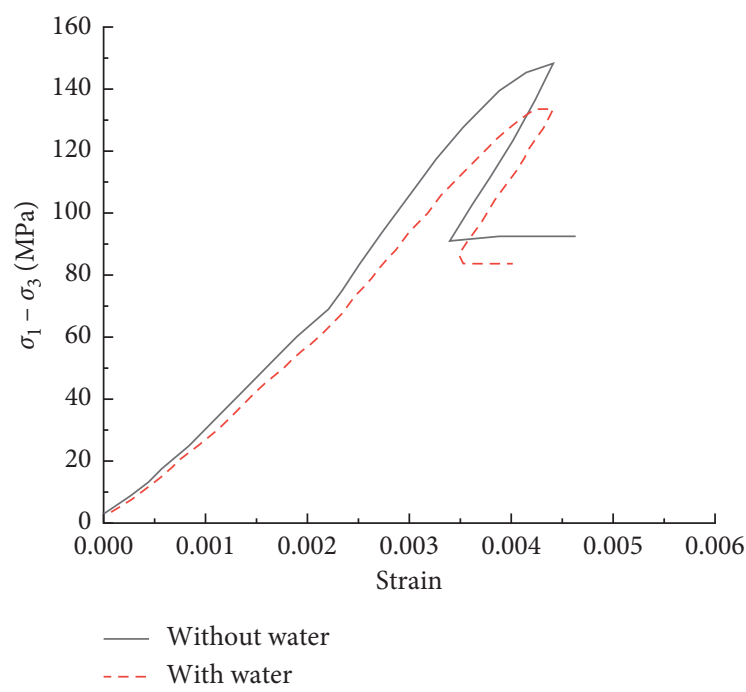

(a)

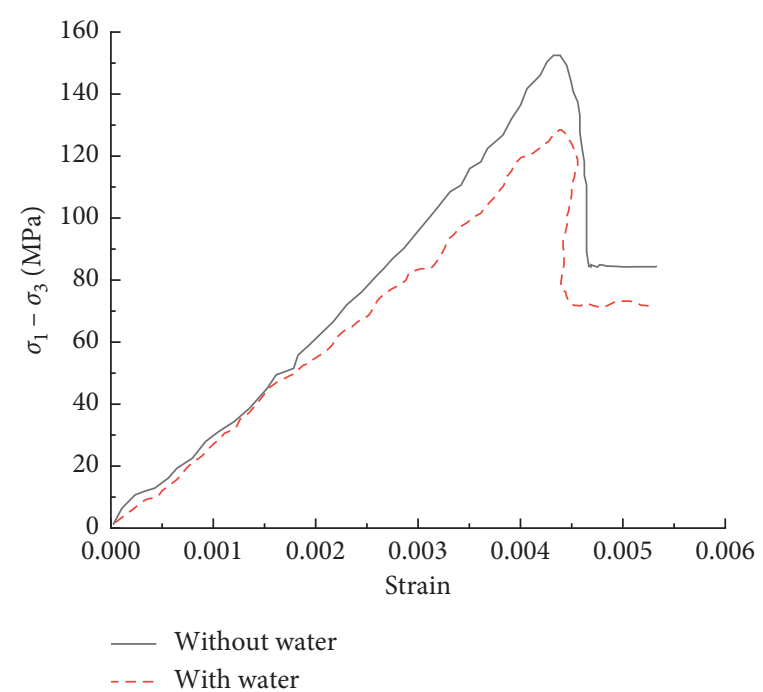

(b)

Figure 3: Stress curves of unloading rock with and without water pressure: (a) results of the experiment and (b) results of the simulation.

\section{Results of Numerical Simulation}

4.1. Simulation Results with and without Water Pressure. First, the prepeak unloading of rocks with or without water pressure was simulated. The rock at a depth of $800 \mathrm{~m}$ was selected, and its gravity stress was approximately $20 \mathrm{MPa}$. The confining pressure was $0.6-0.8$ times of the gravity stress. In this simulation, the confining pressure was $15 \mathrm{MPa}$. The simulation process of unloading rock with water pressure was similar to that without water pressure. On the basis of the model without water pressure, pore water pressure $p_{3}$ and $p_{4}$ were applied to the upper and lower boundaries of the model, which were, respectively, $8 \mathrm{MPa}$ and $10 \mathrm{MPa}$. According to the change of acoustic emission and permeability coefficient with stress, the initiation of new fractures, the expansion of fractures, and the evolution of permeability of seepage rock were studied in the process of unloading.

4.1.1. Changes of Axial Stress and Acoustic Emission and Fracture Mode. By comparing and analyzing Figures 4 and 5 , it could be seen that the number of acoustic emissions reached the maximum 289 when the unloading model without water pressure was at step 80, and almost no acoustic emission occurred before this. The ultimate fracture 


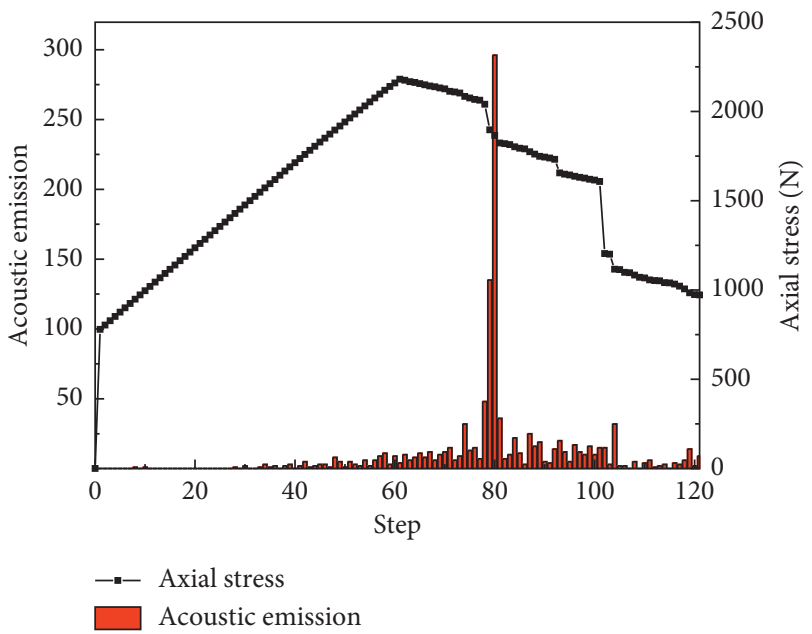

(a)

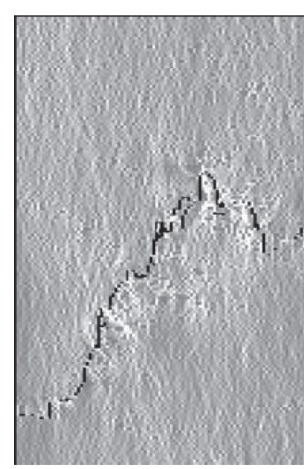

(b)

FIGURE 4: (a) AE and axial stress and (b) fracture mode of unloading rock without water pressure.

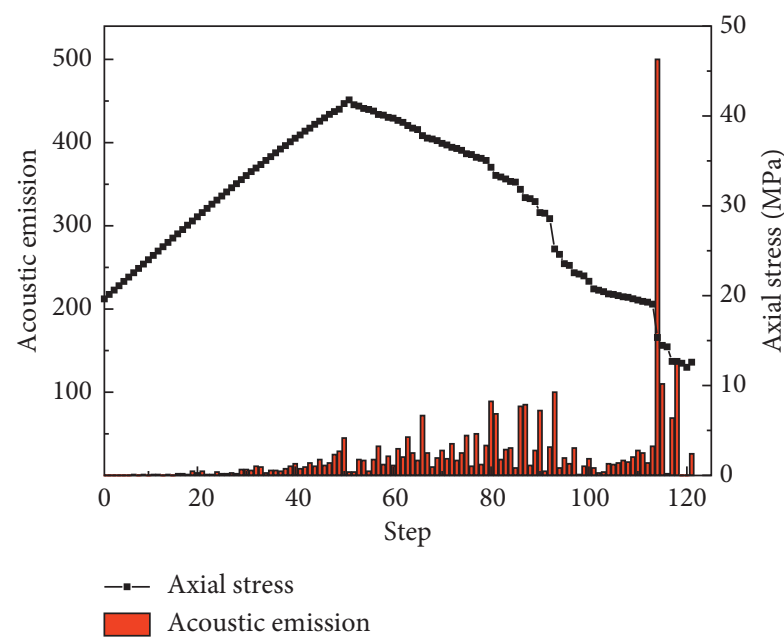

(a)

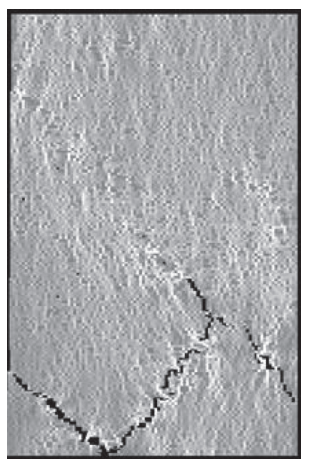

(b)

FIgURE 5: (a) AE and axial stress and (b) fracture mode of unloading rock with water pressure.

mode of the rock was brittle failure. The fracture started from the lower left corner to the upper right. The model with water pressure is different from the model without water pressure. Acoustic emission occurred before the maximum number of acoustic emissions in the unloading model with water pressure. The initial damage was earlier than the model without water pressure. The number of acoustic emissions reached the maximum 482 when the unloading model with water pressure was at step 115, and it showed more brittleness. Because the water pressure at the bottom boundary of the model was greater than that at the top boundary, the failure of the model mainly occurred in the lower part of the model.

\subsubsection{Permeability Coefficient and Seepage Vector.} Figures 6 and 7 are the permeability coefficient change curve and seepage vector diagram of the unloading rock with water pressure, respectively. During the loading process, the primary pores and microfractures gradually closed and the permeability coefficient of rock decreased. During the unloading stage, the permeability coefficient increased and even abruptly changed because of the continuous initiation, expansion, and acceleration of rock microfractures. The seepage path became increasingly obvious, and the seepage vectors were concentrated around the fracture zone.

\subsection{Simulation Results of Different Water Pressure Differences.} In order to explore the failure process of confining pressure unloading rocks with different water pressure differences, the following simulation schemes were made, as shown in Table 2. The physical and mechanical parameters and simulation steps of the rock were consistent with the previous simulation process with or without water pressure.

According to the numerical simulation calculation results of confining pressure unloading rock with different water pressure differences, the strength characteristics and 


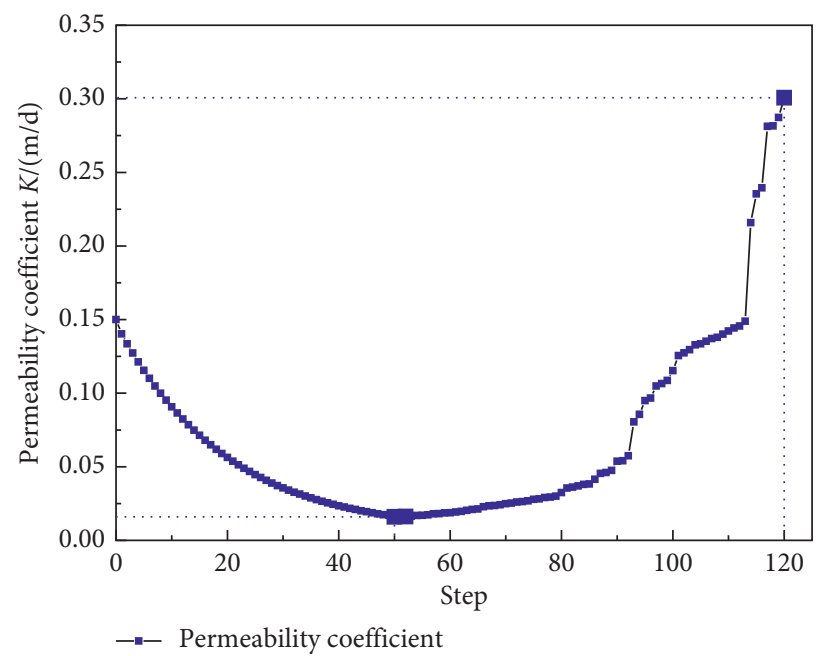

FIGURE 6: Permeability coefficient curve of unloading rock with pore water pressure.

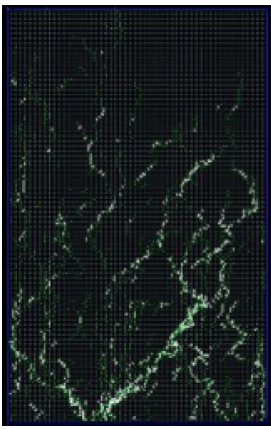

(a)

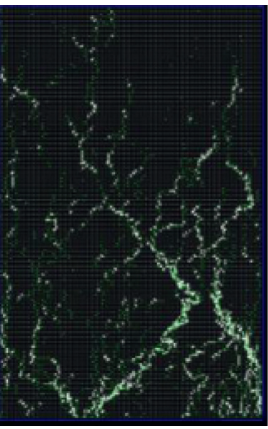

(b)

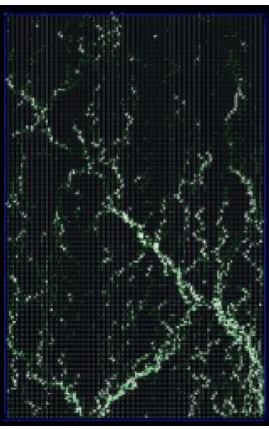

(c)

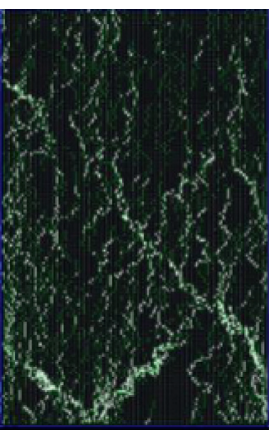

(d)

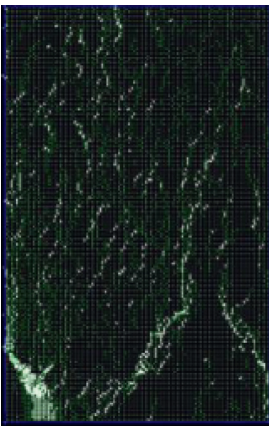

(e)

FIGURE 7: Seepage vector in the process of unloading rock with pore water pressure: (a) step 87, (b) step 89, (c) step 91, (d) step 93, and (e) step 101 .

TABLE 2: Numerical simulation scheme of different water pressures.

\begin{tabular}{lcccc}
\hline Model & $\begin{array}{c}\text { Confining pressure } p_{2} \\
(\mathrm{MPa})\end{array}$ & $\begin{array}{c}\text { Upper water pressure } p_{3} \\
(\mathrm{MPa})\end{array}$ & $\begin{array}{c}\text { Lower water pressure } p_{4} \\
(\mathrm{MPa})\end{array}$ & $\begin{array}{c}\text { Water pressure difference } \Delta p \\
(\mathrm{MPa})\end{array}$ \\
\hline 1 & & & 6 & 2 \\
2 & 15 & 4 & 8 & 4 \\
3 & & & 10 & 6 \\
\hline
\end{tabular}

failure evolution of confining pressure unloading rocks with different water pressure differences are analyzed from three perspectives, including the models of rock fracture, the changes of axial stress and acoustic emission and permeability coefficient during the experiment, and relationship between unloading and permeability coefficient.

4.2.1. Models of Rock Fracture. Figures 8 and 9 are the final fracture and seepage vector of rock specimens with different water pressure differences. It can be seen from Figure 8 that with the increase in water pressure difference, the range and degree of rock fracture increase continuously. The seepage vector distribution of $\Delta p=2 \mathrm{MPa}$ in Figure 9 is relatively uniform, indicating that the fracture is not too large. With the increase in water pressure difference, the more seepage vectors are generated near the fracture zone. This is in accordance with the law of optimizing the seepage path, that is, the velocity of macrofractures is larger than that of microfractures [16].

4.2.2. Changes of Axial Stress and Acoustic Emission and Permeability Coefficient. Figures 10 and 11 are the AE and axial stress and permeability coefficient of rock specimens with different water pressure differences. It can be seen from Figure 10 that during the initial loading stage, the rock with different water pressure difference has no acoustic emission, and the rock has not been damaged; as the calculation proceeds, small failure points and acoustic emission appear. 


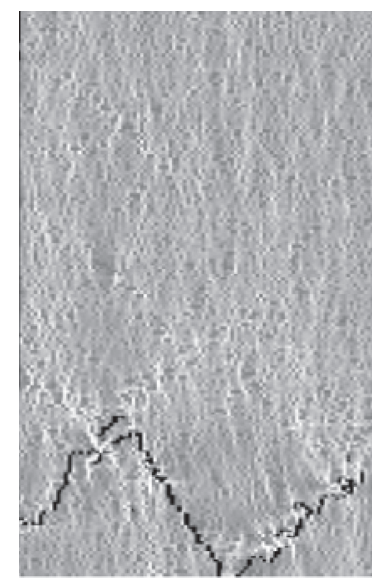

(a)

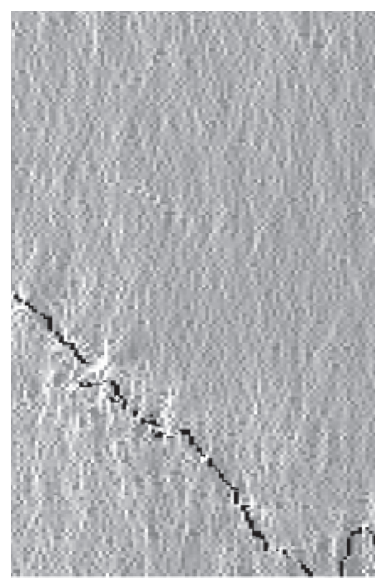

(b)

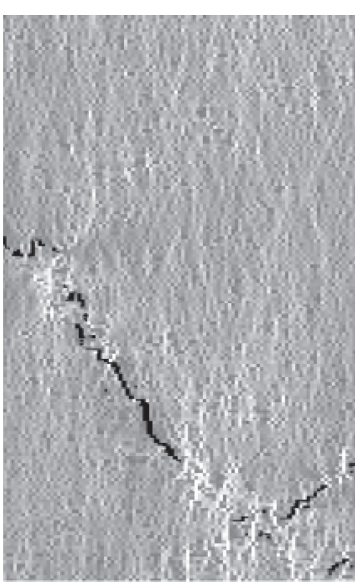

(c)

FIgURE 8: Fracture mode of unloading rock with pore water pressure: (a) $\Delta p=2 \mathrm{MPa}$, (b) $\Delta p=4 \mathrm{MPa}$, and (c) $\Delta p=6 \mathrm{MPa}$.

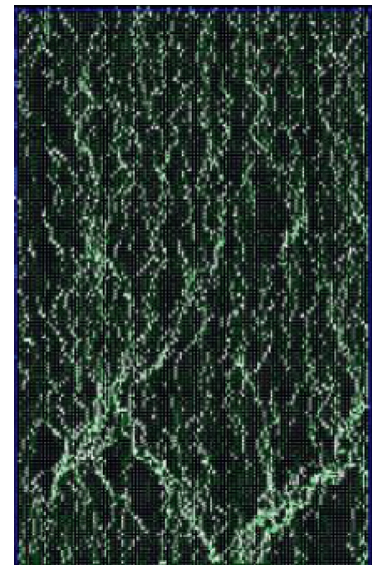

(a)

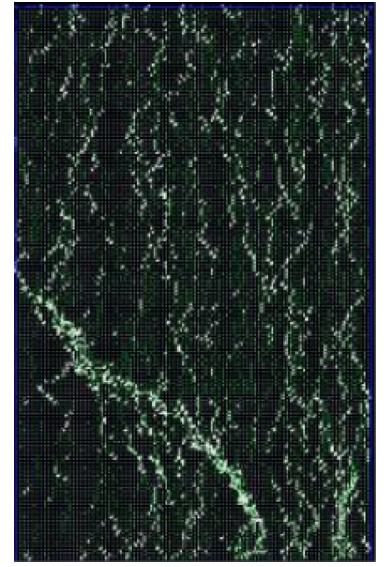

(b)

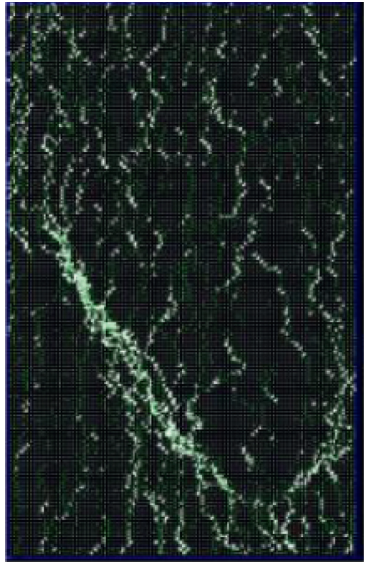

(c)

FIGURE 9: Seepage vector of unloading rock with pore water pressure: (a) $\Delta p=2 \mathrm{MPa}$, (b) $\Delta p=4 \mathrm{MPa}$, and (c) $\Delta p=6 \mathrm{MPa}$.

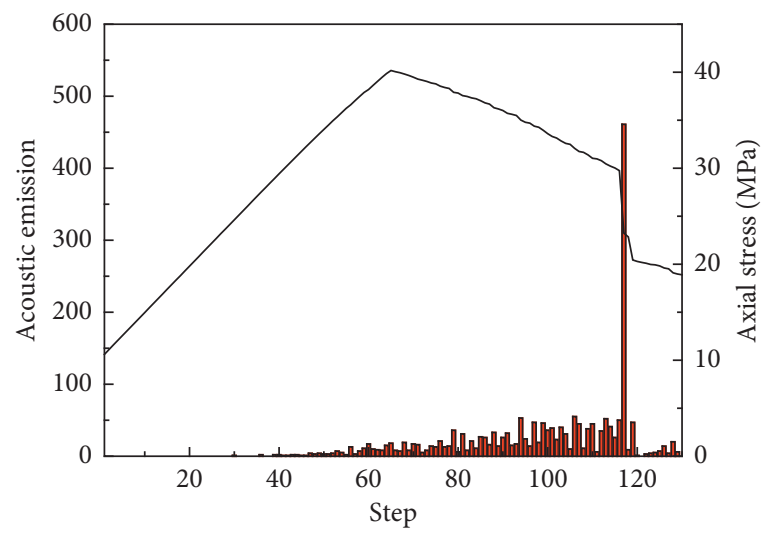

Acoustic emission Axial stress

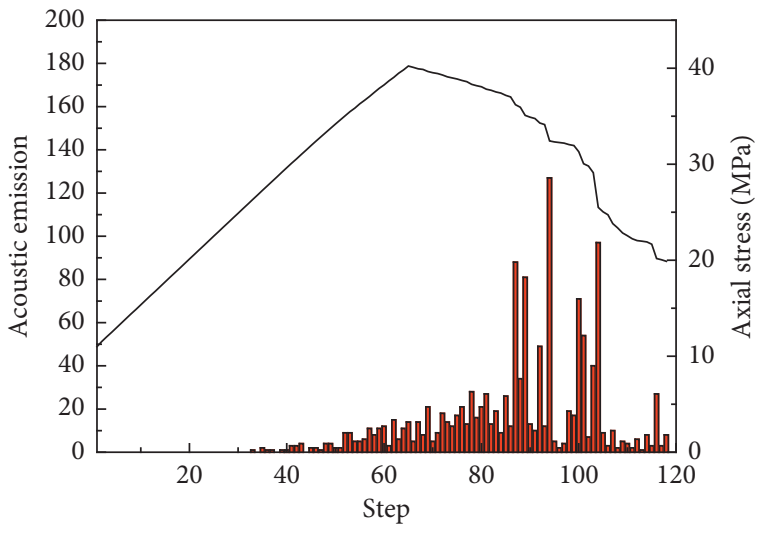

Acoustic emission Axial stress

(a)

Figure 10: Continued. 


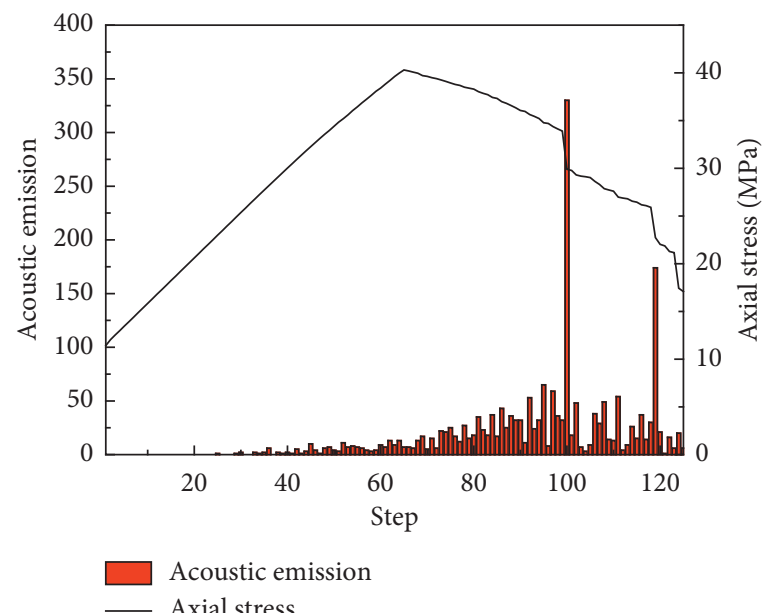

(c)

FIGURE 10: $\mathrm{AE}$ and axial stress of unloading rock with different pore water pressure: (a) $\Delta p=2 \mathrm{MPa}$, (b) $\Delta p=4 \mathrm{MPa}$, and (c) $\Delta p=6 \mathrm{MPa}$.

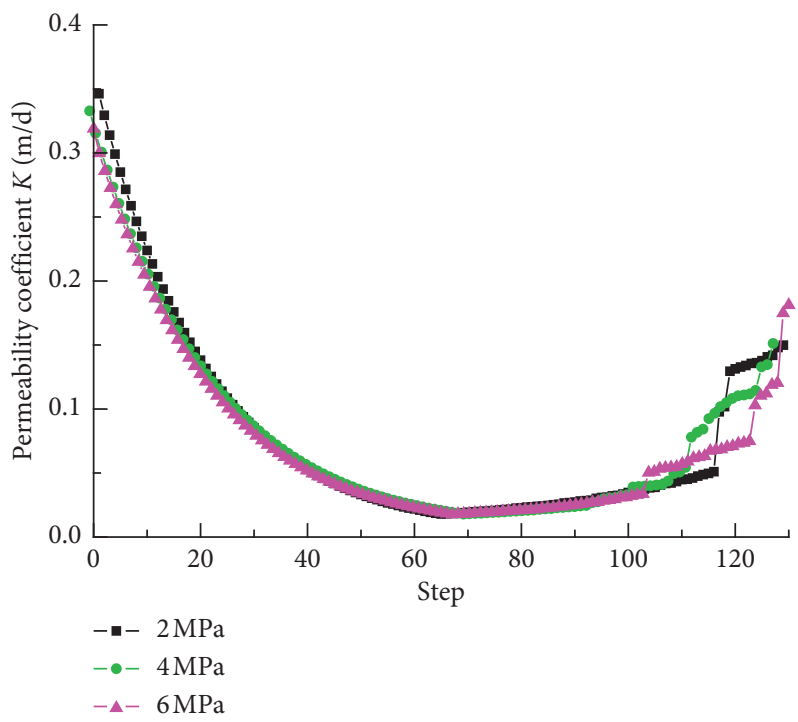

FIgURE 11: Permeability coefficient of unloading rock with different pore water pressure.

When the acoustic emission reaches the maximum, it indicates that the rock has been greatly damaged. When the water pressure difference is $2 \mathrm{MPa}, 4 \mathrm{MPa}$, and $6 \mathrm{MPa}$ and the corresponding load step is 117,97 , and 95, the acoustic emission number reaches its maximum value. It shows that the number of running steps to make rock failure decreases with the increase in water pressure difference. It can be seen from the change process of permeability coefficient in Figure 11 that rock failure modes with different pressure differences are basically same; during the loading process, the primary pores and microcracks gradually closed and the permeability decreases; in the unloading stage, the fractures constantly sprout, expand, and penetrate and the permeability increases continuously and even jumps. Coefficient. To further describe the relationship between unloading volume and permeability coefficient, the unloading ratio of effective stress is introduced. It is the ratio of the difference between the initial stress and the effective stress corresponding to a load step in the unloading process and the initial stress, which is given as follows:

$$
\eta=\frac{\sigma_{0}-\sigma_{i}}{\sigma_{0}} \text {. }
$$

In the formula, $\eta$ is the unloading ratio of effective stress, $\sigma_{0}$ is the initial stress, and $\sigma_{i}$ is the stress value corresponding to a load step in the unloading process.

Figure 12 shows the relationship between the permeability coefficient and the unloading when the water pressure difference is $2 \mathrm{MPa}, 4 \mathrm{MPa}$, and $6 \mathrm{MPa}$. In the unloading elastic stage, the permeability coefficient increases little and changes little. When entering the plastic stage, the reduction of confining pressure increases the rock fracture and the brittleness of the rock. The deformation of rock changes 


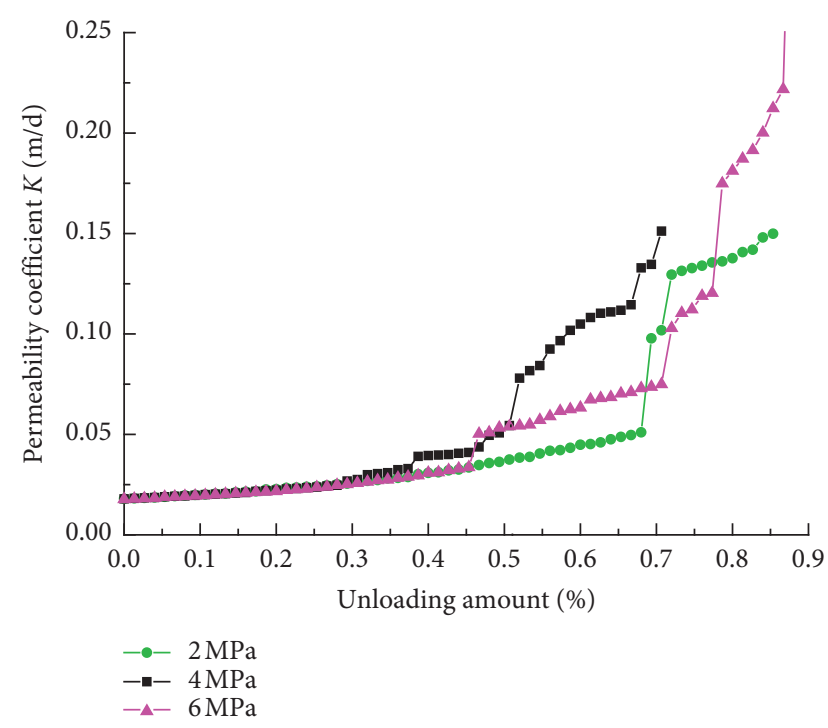

FIGURE 12: The relationship between unloading and permeability coefficient.

from compacting deformation to dilating deformation. Percolation transitioned from the percolation of compressed pores to the percolation of shear fractures. The permeability coefficient increased greatly. The penetration of unloading rock with different water pressure differences is also quite different. When the water pressure difference is $2 \mathrm{MPa}$, $4 \mathrm{MPa}$, and $6 \mathrm{MPa}$ and the corresponding unloading capacity is $68.15 \%, 50.66 \%$, and $45.58 \%$, the permeability has obviously increased. It shows that with the increase in water pressure difference, the unloading quantity to make rock failure becomes smaller and smaller. In addition, when $p_{4}$ is $6 \mathrm{MPa}, 8 \mathrm{MPa}$, and $10 \mathrm{MPa}$, the permeability coefficient is basically $0.0178 \mathrm{~m} / \mathrm{d}$ at the initial stage of unloading, and the permeability coefficient after failure is $0.149 \mathrm{~m} / \mathrm{d}, 0.1512 \mathrm{~m} /$ $\mathrm{d}$, and $0.2343 \mathrm{~m} / \mathrm{d}$, respectively. It is 8.37 times, 8.51 times, and 13.16 times the original. It indicates that with the increase in water pressure difference, the change of permeability coefficient increases with the failure of rock. It shows that the permeability has changed greatly after rock failure. The water flow channel is pores composed of compacted particles, which are transformed into continuous cracks formed by shear failure.

\section{Conclusions}

According to the comparative analysis of the simulation results, the following conclusions can be obtained:

(1) The unloading rock without water pressure is a brittle failure. The initial damage of the unloading model with water pressure is earlier than that of the model without water pressure. The water pressure at the bottom boundary of the model is greater than that at the top boundary, so the failure of the model mainly occurs at the bottom.

(2) With the increase in water pressure difference, the extent and degree of rock fracture increase. The increase in water pressure difference makes the seepage path gradually obvious, and a larger seepage vector is generated near the fracture zone.

(3) The rock failure modes under different water pressure differences are basically identical; in the loading process, the primary pores and microfractures gradually close and the permeability of rock decreases, and in the unloading stage, the fractures constantly sprout, expand, and penetrate and the permeability increases and even jumps.

(4) In the elastic stage of unloading, the permeability coefficient increases little. When entering the plastic stage, the reduction of confining pressure causes the rock deformation to change from compacted deformation to dilated deformation, the opening of the fracture increases, and the corresponding seepage transition from compressed pore seepage to shear fracture seepage and the permeability coefficient increase greatly. With the increase in water pressure difference, the amount of unloading when the failure is reached becomes smaller and smaller.

\section{Data Availability}

The data used to support the findings of this study are available from the corresponding author upon request.

\section{Conflicts of Interest}

The authors declare that they have no conflicts of interest.

\section{Acknowledgments}

This research was supported by the First-Rate Discipline Construction Program of Mining Engineering (01LX03303).

\section{References}

[1] X. Chen and L. Lu, "Experimental study on rock unloading mechanical properties under high confining pressure and high water pressure," Journal of Rock Mechanics and Engineering, no. S1, pp. 2694-2699, 2008.

[2] P. Jia and C. Tang, "Numerical simulation study on unloading mechanical properties of intact rock," in Proceedings of the Ninth National Conference on Rock Mechanics and Engineering, p. 4, Liaoning, China, 2006.

[3] Y. Wang, Z. Xu, and B. Su, "Fully coupled analysis of seepage and stress-elastoplasticity of complex fractured rock mass," Chinese Journal of Rock Mechanics and Engineering, no. 3, pp. 177-181, 2003.

[4] Z. Chang, Y. Zhao, Y. Hu, and D. Yang, "Theoretical and experimental research on the seepage law of a single fracture under three-dimensional stress," Chinese Journal of Rock Mechanics and Engineering, vol. 23, no. 4, pp. 620-624, 2004.

[5] R. Huang, X. Wang, and L. Chen, "Analysis of hydraulic fracturing in the process of water gushing in deep tunnels," Chinese Journal of Rock Mechanics and Engineering, no. 9, pp. 573-576, 2000.

[6] K.-B. Min, J. Rutqvist, C.-F. Tsang, and L. Jing, "Stress-dependent permeability of fractured rock masses: a numerical 
study," International Journal of Rock Mechanics and Mining Sciences, vol. 41, no. 7, pp. 1191-1210, 2004.

[7] Q. Wu, B. Zhu, and S. Liu, "Analysis of fluid-solid coupling simulation method for lagging water inrush in mine fractured structural zone and determination of lag time," Chinese Journal of Rock Mechanics and Engineering, vol. 30, no. 1, pp. 93-104, 2011.

[8] L. Li, C. Tang, Li Gen, and T. Yang, "Analysis of damage evolution and delayed water inrush mechanism of coal floor with hidden faults," Chinese Journal of Geotechnical Engineering, vol. 31, no. 12, pp. 1838-1844, 2009.

[9] R. Liu, L. Yu, and Y. Jiang, "Quantitative estimates of normalized transmissivity and the onset of nonlinear fluid flow through rough rock fractures," Rock Mechanics and Rock Engineering, vol. 50, no. 4, pp. 1063-1071, 2016.

[10] L. Z. Xie, C. Gao, L. Ren, and C. B. Li, "Numerical investigation of geometrical and hydraulic properties in a single rock fracture during shear displacement with the Navier-Stokes equations," Environmental Earth Sciences, vol. 73, no. 11, pp. 7061-7074, 2015.

[11] Y. Zhang, L. Peng, Q. Guo, M. Cai, F. Ren, and W. Xu, "Research progress on deformation and failure mechanism of hydraulic exchange fractured rock mass," Journal of Harbin Institute of Technology, vol. 52, no. 6, pp. 21-41, 2020.

[12] K. M. Terekhov and Y. V. Vassilevski, "Finite volume method for coupled subsurface flow problems, I: Darcy problem," Journal of Computational Physics, vol. 395, pp. 298-306, 2019.

[13] A. P. S. Selvadurai, "The Biot coefficient for a low permeability heterogeneous limestone," Continuum Mechanics and Thermodynamics, vol. 31, no. 4, pp. 939-953, 2019.

[14] S. Zhang, W. Qiao, Y. Wu, Z. Fan, and L. Zhang, "Experimental study on seepage characteristics of microfracture with different aperture," Scientific Reports, vol. 10, no. 3, 2020.

[15] Z. Li, Z. Zhu, Y. Shi, and X. Ni, "Experimental study on unloading strength characteristics of rock under high confining pressure and high water pressure," Journal of Hohai University, vol. 37, no. 2, pp. 162-165, 2009.

[16] Y. Guo, X. Jiang, and Z. Song, "Analysis of seepage evolution law of rock mass based on the numerical algorithm considering strength weakening water absorption," Arabian Journal of Geosciences, vol. 11, no. 13, 2018. 